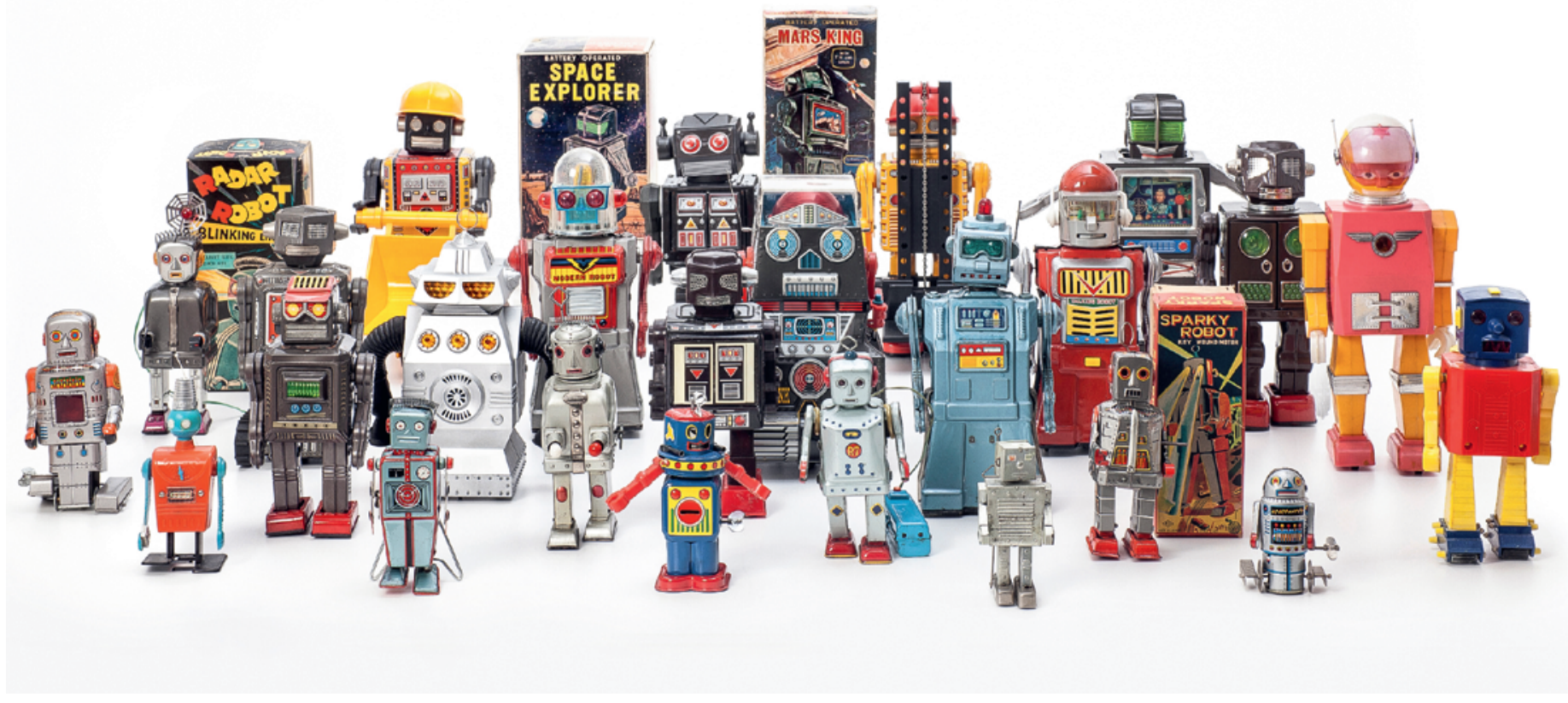

Verschiedene Hersteller: Historische Spielzeugroboter, 1956-1980

\title{
Hello, Robot.
}

\section{Erhard Taverna}

Dr. med., Mitglied der Redaktion

Wer sich umfassend über den aktuellen Zustand der Robotik informieren will tut gut daran die Ausstellung «Hello, Robot. - Design zwischen Mensch und Maschine» im Gewerbemuseum Winterthur zu besuchen. Die Beteiligung namhafter Institutionen ist ausserordentlich. Das Projekt ist eine Koproduktion des $\mathrm{Ku}$ ratorenteams mit dem Vitra-Design-Museum, dem MAK - Österreichisches Museum für angewandte Kunst und dem Design-Museum Gent, unterstützt von der Kulturstiftung des Bundes. Vier Themenblöcke versuchen eine Gliederung jener technologischen Kraft,

\section{Exponate aus jedem denkbaren täglichen} Bereich, Studien, Visionen, Phantasmen, Hoffnungen und Ängste bekommen eine Sprache.

die zurzeit am schnellsten unser Zusammenleben verändert: Science und Fiction - Programmiert auf Arbeit - Freund und Helfer - Eins werden. Exponate aus jedem denkbaren täglichen Bereich, Studien, Visionen, Phantasmen, Hoffnungen und Ängste bekommen eine Sprache. Ein ausführlicher Katalog vertieft die Ausstellungsinformationen und ergänzt sie durch Kommentare, Interviews und philosophische Betrachtungen.
Unübersehbar ist die weit fortgeschrittene Cyborgisierung durch externe Geräte wie Laptop, Smartphone oder intelligente Prothesen. Ihre Datenströme verändern uns in allen Lebensbereichen mit zunehmender Dynamik. Die Reise geht von Paro, dem therapeutischen Robbenbaby, zu sprachgesteuerten, digitalen Assistenten wie Echo, Siri oder Alexa, von Industrieanlagen zu bewaffneten Drohnen, vom mobilen Marslabor Curiosity zu Leka, dem Smart Toy für autistische Kinder oder zum Exoskelett für gelähmte Patienten. Es macht keinen Sinn, die vielen Exponate aufzuzählen; man sollte sich einen Überblick verschaffen und danach möglichst viel Zeit in eine individuelle Auswahl dieser klug arrangierten Objekte investieren oder mehrmals die Ausstellung besuchen.

Die Welt der gegenwärtigen KI-Welle wird neben dem Militär von Firmen wie Facebook, Google oder Baidu vorangetrieben, die in allen möglichen Kontexten Geld verdienen wollen.

Noch leidet die Künstliche Intelligenz an einem Körperdefizit, das durch menschliche Vertreter ausgeglichen werden muss. Wie lange dauert es noch bis das Machine Learning oder Deep Learning ohne Verkörperung durch uns Gebraucher auskommt? Es ist beun- 
ruhigend auf solche, zumindest für uns existenzielle, Fragen keine Antworten zu kennen

Für einige ist die Marke Mensch am Auslaufen, sie denken über die postanthropozentrische Wende nach, in der die Vormachtstellung der Spezies zugunsten einer hybriden Mischwelt aufgegeben wird: «Ein Exodus der emotional besonders schwierig ist und mit einem Gefühl von Verlust und Schmerz verbunden sein kann.»

Noch leidet die Künstliche Intelligenz an einem Körperdefizit, das durch menschliche Vertreter ausgeglichen werden muss.

Stanislaw Lem, der polnische Science Fiction Schreiber hat vor sechzig Jahren darüber nachgedacht [1]. In einer fernen Galaxie erfährt der verliebte Roboterprinz eine Schnellbleiche in Sachen menschlicher Evolutionsgeschichte: "Aus nasskalten Dünsten und Brünsten, Sud und Sudelei brütete sich das Geschlecht der Bleichlinge aus. Zuerst waren sie Schimmelwucherung und Gekreuch, sodann flossen sie aus den Ozeanen an Land und lebten davon, dass einer den anderen verschlang.
Und je mehr sie einander verschlangen, umso mehr wurden es ihrer; schliesslich richteten sie sich auf, indem sie ihre klebrige Wesenheit an Kalkgerüste hängten und begannen Maschinen zu bauen. Aus diesen Urweltmaschinen entstanden die denkenden Maschinen. Diese zeugten die gescheiten Maschinen. Diese aber ersannen die vollkommenen Maschinen.»

Eine Posterwand des kanadischen Schriftstellers und Künstlers Douglas Coupland kann man als Beginn oder Ende der Ausstellung lesen, ein Orakel für das digitale Zeitalter:

THE PAST IS NOW USELESS - IT'S ALL HAPPENING WAY FASTER THAN WE THOUGHT - A LOT OF PEOPLE DON'T WANT PROGRESS - THE UNANTICIPATED SIDE EFFECTS OF TECHNOLOGY DICTATE THE FUTURE usW.

\section{Bildnachweis}

Ausstellungsfoto: @ Gewerbemuseum Winterthur / Foto: Michael Lio Historische Spielzeugroboter: @ Privatsammlung / Foto: Andreas Sütterlin, 2016

\section{Literatur}

1 Lem S, Robotermärchen, Phantastische Bibliothek, Suhrkamp Taschenbuch 1982

\section{Hello, Robot.}

Ausstellung im Gewerbemuseum Winterthur, 27. Juni bis 4. November 2018

Öffnungszeiten: Di, Mi, Fr, Sa, So: 10.00-17.00 Uhr; Do: 10.00-20.00 Uhr; Mo: geschlossen.

Bitte beachten Sie die speziellen Öffnungszeiten an Feiertagen. Weitere Informationen online unter: www.gewerbemuseum.ch

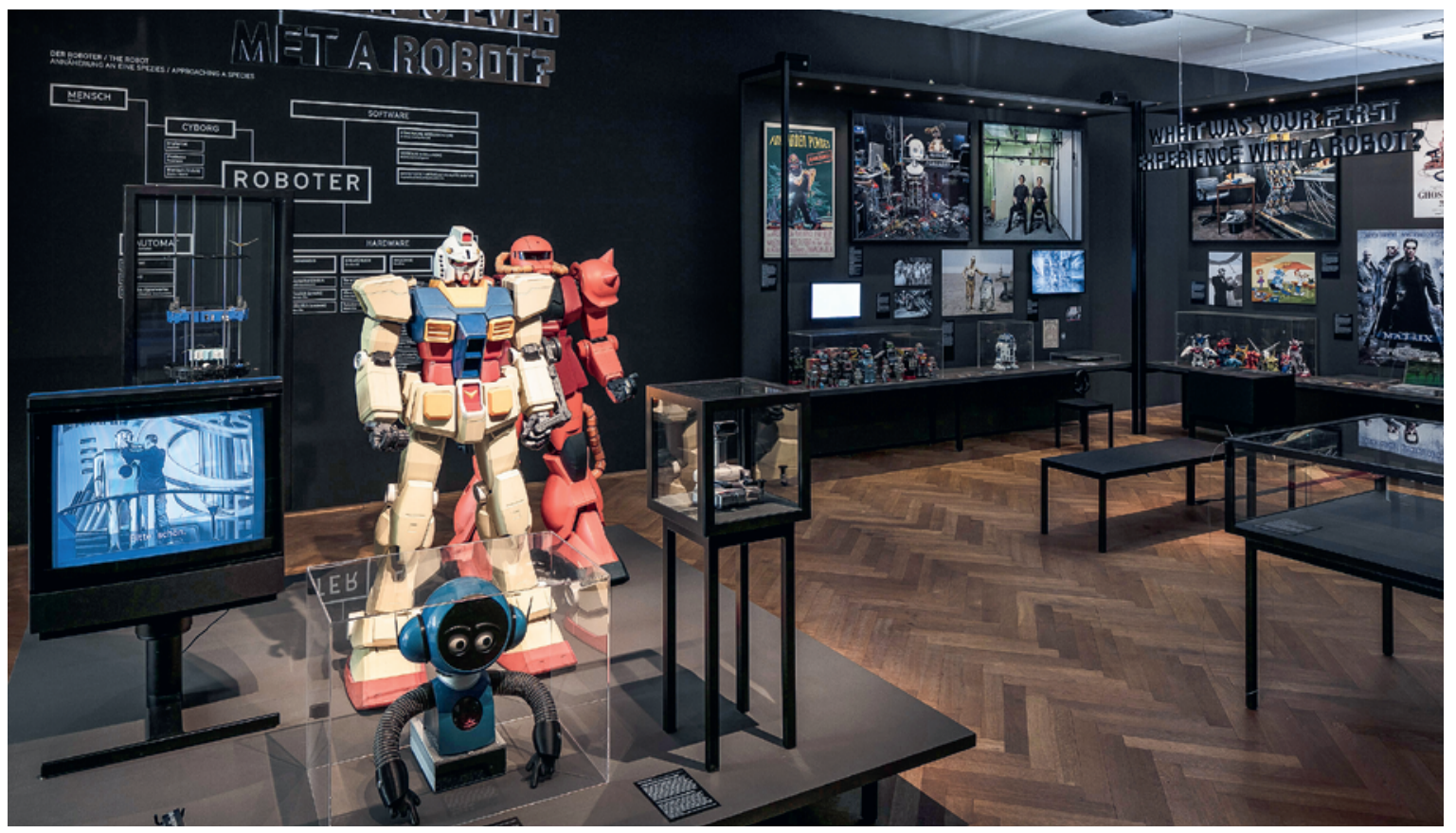

